\title{
Sacrifice and Sorting in Clubs
}

\author{
Jean-Paul Carvalho* \\ Department of Economics \& \\ Institute for Mathematical Behavioral Sciences \\ University of California, Irvine
}

\begin{abstract}
In club models of religion, sacrifices demanded by religious groups promote efficient production of club goods by screening out free riders. An alternative, complementary view is that religious clubs provide a means of sorting, matching individuals with similar characteristics. Sorting differs from screening in that it operates on traits that do not directly affect club goods production. This paper explores the role of sacrifice in sorting among religious clubs when individuals prefer to interact with their own type. Despite this own-type bias, the usual freerider problem in club goods production can inhibit sorting among groups. Prohibitions and demands for stigmatizing behavior can solve this problem. Costly sacrifices are demanded, not by groups catering to the majority, but by those attracting rare/exotic types. The rarer the type, the more costly the sacrifice required to achieve sorting.
\end{abstract}

This version: 30 October 2015

JEL Classification: C72, C73, Z1

Keywords: Club Goods, Economics of Religion, Sorting

*This paper has benefitted from comments by Michael McBride and Cole Randall Williams, and research assistance by Helen Yu. 


\section{Introduction}

Religious groups tend to have a club structure, collectively producing club goods such as religious services, charitable activities and mutual insurance (Iannaccone 1992, Berman 2000). There are well known free-rider problems in collective production (Olson 1965, Cornes \& Sandler 1986). In the canonical model of religious clubs developed by Iannaccone (1992), demands for costly sacrifice, including stigmatizing forms of dress and ritual as well as dietary and sexual restrictions, can ameliorate the free-rider problem and raise the welfare of group members. This works in two ways. Firstly, such requirements act as a per-unit tax on outside activity, thereby inducing substitution of time and money toward group activities. Secondly, it screens out less committed types that are more likely to free ride. Let us call these substitution and screening effects the 'economic role' of sacrifice.

This paper studies a highly complementary, but neglected, 'social role' for sacrifice in religious clubs. Religious clubs, like many other types of club, play an important role in facilitating social interactions. We assume that individuals exhibit own-type bias, preferring to interact exclusively with people possessing similar traits. This creates a demand for groups that sort based on 'economically neutral' traits, such as ethnolinguistic background, taste in art and music, and hobbies. ${ }^{1}$ Such traits do not directly affect one's propensity to contribute to a group once one has joined. They are, however, likely to determine with whom one wishes to interact and hence which group one joins. ${ }^{2}$

Sorting occurs when in equilibrium each group is homogeneous. If this takes place, own-type bias at the individual level is reflected in homogeneous groupings at the macro level. This is to be distinguished from the screening of free riders in standard models. A propensity to free ride directly affects production of club goods and can thus be thought of as an economically relevant trait. Our focus is on economically neutral traits, which play a role in social interactions and do not directly affect club goods provision. ${ }^{3,4}$

On the one hand, the social function of religious clubs in facilitating social interactions

\footnotetext{
${ }^{1}$ This reminds one of the statement attributed to Rev. Martin Luther King Jr, that Sunday morning is the most segregated hour in the nation.

${ }^{2}$ Relatedly, Carvalho (2015a) shows that certain forms of cultural diversity can lead to the breakdown of coordination in social interactions.

${ }^{3}$ For example, Kalmijn (1998) finds that cultural traits are more important than economic occupational status in determining assortative mating.

${ }^{4}$ The distinction between sorting and screening will become sharper once we specify the model.
} 
is rather immediate and obvious. Iannaccone \& Berman (2006) describe how sects provide "social networks [that] help members form joint business ventures, establish long-term friendships, and find suitable marriage partners" [p. 118]. On the other hand, we are unaware of a model in which religious groups sort individuals based on neutral traits. As it turns out, the social function of religious groups, in matching individuals with similar characteristics, is inextricably linked to standard economic considerations in terms of limiting free riding. Individuals would like to join a homogeneous group due to own-type bias. They would also like to join a small group to limit free riding (Olson 1965). As we shall see, these objectives are in conflict with one another.

Before describing the results of our analysis, let us review existing evidence on own-type bias and sorting in social interactions. An important and related concept in the social networks literature is homophily. Due to Lazarsfeld \& Merton (1954), the term has been used to refer both to a preference for interacting with similar individuals - its literal meaning is 'self love' - and empirical patterns in which parties to a social interaction tend to be similar along a range of characteristics, including ethnicity, religion, age and gender (McPherson et al. 2001). Homophily can arise via several channels in the network formation process, namely through constraints, individual preferences and group preferences.

Firstly, when choosing relationships, an individual's choice set is often determined by his ethnicity, geographical location and other factors. An individual's most important relationships tend to be with family members, who are similar due to intergenerational cultural transmission (Cavalli-Sforza \& Feldman 1981, Boyd \& Richerson 1985, Bisin \& Verdier 2000). Individuals tend to marry homogamously (Kalmijn 1998), attend schools that are already heavily sorted based on income, ethnicity and other factors, and rely on friends and relatives to find jobs (Bradshaw 1973), choose religious groups (Stark \& Bainbridge 1980) and make many other important life choices. Thus, interactions tend to occur among individuals who share ascriptive traits and exposure to similar cultural influences, simply because of the institutions determining matching in social interactions. In the literature, this is called the baseline level of homophily.

Individuals and groups may also have a preference for similarity, which we term own-type bias, and thus seek a greater level of sorting than the baseline level. The level of assortativity that occurs above and beyond the baseline level is referred to as 'inbreeding homophily' (McPherson et al. 2001). This is what is referred to as sorting in this paper. Own-type bias 
appears to drive sorting in a wide range of settings, including racial sorting in firms (Reskin et al. 1999), schools (Shrum et al. 1988) and close social relationships (Marsden 1987). In a study of online dating systems, Fiore \& Donath (2005) find that individuals tend to seek partners who have similar characteristics to themselves.

It may seem natural that own-type bias would lead individuals to self select into homogenous groups. We show that this is not always the case in religious groups, due to their club structure. The sorting problem and standard free-rider problem interact in interesting ways. Due to free riding in large groups, individuals consider not only the composition of their group, but also the size. The desire to achieve optimal group size can inhibit self sorting. Hence individuals can benefit from an institution that matches agents with similar characteristics in social interactions. We propose that religious groups play such a role, selecting for particular types of individuals. Since personality types are deep, not immediately observable traits, groups cannot directly detect and exclude particular types, but must instead design a sorting mechanism. It turns out that sorting can be achieved through demands for costly sacrifice. Hence the seemingly bizarre prescriptions and proscriptions imposed by religious groups, identified by Iannaccone (1992, p. 273), can have an important function beyond their usual role in limiting free riding.

To be more specific, suppose that society consists of two personality types, a minority type and a majority type, and two religious clubs. When there are two clubs, a club consisting exclusively of minority-type individuals is smaller than a homogenous majority-type club. Hence it faces a less severe free-rider problem and is more efficient at producing club goods. This virtue may attract majority-type individuals to join the minority group, despite their own-type bias. To overcome this barrier to sorting, the minority group can impose a membership cost, i.e. a demand for costly sacrifice. We demonstrate that there is always a membership cost that supports perfect sorting. Due to own-type bias, minority-type individuals receive a greater payoff from joining the minority group than majority-type individuals. Hence they are willing to bear the membership cost, while a deviating majority-type individual is not. Thus a new social role for costly sacrifice is identified.

The club structure of religious groups has been emphasized by Iannaccone (1992, 1994), Berman (2000, 2009), Iannaccone \& Berman (2006) and McBride (2007, 2015). ${ }^{5}$ In seminal

\footnotetext{
${ }^{5}$ In addition, Carvalho et al. (2015) develop a model of competing groups producing non-congestible club goods.
} 
work, Iannaccone $(1992,1994)$ argued that costly sacrifice can promote efficient club goods production. Aimone et al. (2013) test this theory experimentally, finding that sacrificing returns on private investment boosts club production via substitution and screening channels, with the latter being particularly important. ${ }^{6}$ Our paper contributes to the literature on religious clubs by proposing that sorting is an important function of religious clubs, that the free-rider problem can inhibit sorting, that costly sacrifice plays a new role in overcoming barriers to sorting and that groups catering to rare/exotic types demand costlier sacrifices.

Our results are based in part on the assumption of own-type bias. This appears in the seminal work by Schelling $(1969,1971)$ on residential segregation (see also Young 1998, ch. 2). Schelling shows that residential sorting can occur even when individuals exhibit only a weak form of own-type bias. In the context of religious clubs, we uncover a different disconnect between individual preferences and social outcomes: sorting may fail to occur even when individuals exhibit a fairly strong form of own-type bias. Finally, Currarini et al. (2009) develop a model of friendship network formation in which own-type bias and bias in the matching process are shown to generate observed patterns of homophily in social networks. Inter alia, we study the effect of own-type bias, not in decentralized social interactions, but in religious clubs subject to free-rider problems.

\section{The Model}

Let us begin with a baseline model in which all individuals are members of a single club. We shall later introduce a choice of group membership.

Society consists of a finite set of individuals $i \in N$, each endowed with one of two types denoted by $\tau \in\{1,2\}$. There are $n_{1}=q n$ type- 1 individuals and $n_{2}=(1-q) n$ type- 2 individuals, where $n_{2}>n_{1}+1>1$ and $n=n_{1}+n_{2}$. Hence we shall refer to type 1 as the minority type. An individual's types is private knowledge (e.g. deep personality traits), but the distribution of types defined by $q$ is common knowledge.

All individuals live for one period, receiving income of $y$ dollars at the beginning of the period. Individual $i$ purchases $x_{i}$ units of a unique private consumption good, with price

\footnotetext{
${ }^{6} \mathrm{~A}$ related literature in evolutionary biology predicts that cooperative norms proliferate if there is enough assortative matching in a population (see Cooper \& Wallace 2004, and references therein).
} 
normalized to one, and contributes $g_{i}$ dollars to production of a club good. Denote total contributions to the club good by $G \equiv \sum_{i \in N} g_{i}$. The quality of the group is measured by the average contribution $G / n$, which we assume is an individual's payoff from access to the club good. ${ }^{7}$

The novel feature of our model is that players prefer to interact with individuals of their own type. Specifically, each individual receives a 'psychic' payoff of $\alpha$ times the proportion of their own type in the club (excluding themselves), where $\alpha>0$ measures the strength of own-type bias. ${ }^{8}$

A type- $\tau$ individual's utility function is

$$
u_{i, \tau}\left(x_{i}, g_{i}\right)=\ln \left(x_{i}\right)+\frac{G}{n}+\alpha\left(\frac{n_{\tau}-1}{n-1}\right) .
$$

The first term is the payoff from private consumption and the second term is the payoff from access to the club good. The novelty lies in the third term which measures the payoff from social interaction in the club with individuals of one's own type. Note that the second and third terms are additively separable. Hence there is no direct link between an individual's type and his propensity to contribute to the club good. It is in this sense that we refer to types in our model as economically neutral. ${ }^{9}$ It is also in this sense that sorting among religious clubs is different to screening out of free riders.

To ensure solutions are interior, we assume throughout that $y>n$.

The problem for individual $i$ of type $\tau$ is:

$$
\begin{gathered}
\max _{x_{i}, g_{i}} u_{i, \tau}\left(x_{i}, g_{i}\right)=\ln \left(x_{i}\right)+\frac{G}{n}+\alpha\left(\frac{n_{\tau}-1}{n-1}\right), \\
\text { s.t. } y \geq x_{i}+g_{i} .
\end{gathered}
$$

\footnotetext{
${ }^{7}$ More generally, group quality could be made a nonlinear function of total contributions $G$ and group size $n$. Defining group quality as the average contribution captures in a simple fashion two basic properties: quality is increasing in total contributions and (holding $G$ fixed) decreasing in the number of members, due possibly to congestion.

${ }^{8}$ This own-type bias will acquire significance when we introduce a choice of group membership.

${ }^{9}$ In standard models, the second term would vary across types, with some individuals receiving a lower payoff from contributing to the club good. It is such types that a religious group wishes to screen out through demands for sacrifice.
} 
As agents live for one period and the utility function is strictly increasing in both arguments, the budget constraint binds. Rearranging it, we have $x_{i}=y-g_{i}$. Substituting this into the objective function:

$$
\max _{x_{i}, g_{i}} u_{i, \tau}\left(x_{i}, g_{i}\right)=\ln \left(y-g_{i}\right)+\frac{G}{n}+\alpha\left(\frac{n_{\tau}-1}{n-1}\right) .
$$

The first-order condition is:

$$
\frac{1}{y-g_{i}}=\frac{1}{n} \Longrightarrow g_{i}^{*}=y-n
$$

which is positive, since $y>n$ by assumption. It is also independent of $\tau$ and hence the same for all $i \in N$. This defines the unique Nash equilibrium.

Thus contributions to the club good are decreasing in the number of individuals $n$. This is the usual free-rider problem. Indirect utility of a type- 1 individual is

$$
V_{i, 1}(y, n)=\ln (n)+(y-n)+\alpha\left(\frac{q n-1}{n-1}\right) .
$$

Differentiating with respect to $n$, we have:

$$
\frac{1}{n}-1+\alpha\left(\frac{1-q}{(n-1)^{2}}\right)
$$

which is negative for $n$ sufficiently large. The same analysis can be conducted for type-2 individuals. Hence, in a large society, each individual's equilibrium payoff is strictly decreasing in population size $n$. This is the effect of the free-rider problem which will play an important role in the ensuing analysis.

These results can be summarized by the following proposition.

Proposition 1 Suppose that all individuals are members of one group. There exists a unique Nash equilibrium of the game. In this equilibrium:

(i) The optimal contribution to the club good is

$$
g_{i}^{*}=y-n
$$

for each individual $i \in N$. 
(ii) For $n$ sufficiently large, the equilibrium payoff of each individual is strictly decreasing in population size $n$.

\subsection{Sorting Among Religious Clubs}

Now instead of individuals being members of a single group, suppose they first choose to join one of two religious groups $k \in\{1,2\}$. We denote individual $i$ 's membership choice by $m_{i} \in\{1,2\}$. Let $M^{k}=\left\{i: m_{i}=k\right\}$ be the set of individuals who join group $k$. The cardinality of $M^{k}$ is $n^{k}$. The number of type- $\tau$ individuals who join group $k$ is denoted by $n_{\tau}^{k}$.

After observing the number of individuals who join the group, each individual chooses a contribution to their group. Each group produces a separate club good, which only members of that group can access. As before, agent $i$ purchases $x_{i}$ units of a unique private consumption good at unit price and contributes $g_{i}$ dollars to the club good produced by his group. The total contribution to group $k$ is $G^{k} \equiv \sum_{i \in M^{k}} g_{i}$. The group's quality is again its average contribution, $G^{k} / n^{k}$. In addition, each individual receives a payoff of $\alpha$ times the proportion of his own type in the group he joins (excluding himself).

The utility of a type- $\tau$ individual who joins group $k$ is then

$$
u_{i, \tau}\left(x_{i}, g_{i}, m_{i}\right)=\ln \left(x_{i}\right)+\frac{G^{k}}{n^{k}}+\alpha\left(\frac{n_{\tau}^{k}-1}{n^{k}-1}\right) .
$$

Once again the third term is the novelty. This own-type bias means that individuals benefit from joining a homogeneous group composed of their own type.

Define a perfect sorting equilibrium as a subgame perfect equilibrium of the game in which all type-1 individuals join one group and all type-2 individuals join the other. Since for $\alpha>0$ individuals prefer to interact with their own type, it seems natural that such an equilibrium would exist for all positive $\alpha$. As we shall now show, however, sorting may not occur due to the free-rider problem.

Without loss of generality, suppose that all type- 1 agents join group 1 and all type-2 agents join group 2. We shall proceed to show that there is a profitable unilateral deviation if and 
only if $\alpha$ is sufficiently small. In particular, a type- 2 agent will have an incentive to switch to group 1. (It is straightforward to show that a type-1 agent will have no profitable deviation under the conditions of the Proposition.)

Consider a type- 2 agent $j$. Adapting the result in Proposition 1 , if $j$ plays his part in the equilibrium and joins group 2, the optimal contribution by all members of 2 to the club good will be $g_{2}^{*}=y-n_{2}$ (i.e. $n$ is simply replaced by the number of agents in group $2, n_{2}$ ). Thus, $j$ 's payoff from joining group 2, which includes all other type-2 agents only is:

$$
\ln \left(n_{2}\right)+y-n_{2}+\alpha
$$

If $j$ deviates and joins 1 , then group 1 will consist of $j$ plus all type- 1 members, so the optimal contribution by all members of 1 to the club good will be $g_{1}^{*}=y-\left(n_{1}+1\right)$. Thus, $j$ 's payoff from joining group 1 is:

$$
\ln \left(n_{1}+1\right)+y-\left(n_{1}+1\right)
$$

The payoff (3) is less than the deviation payoff (4) if:

$$
\ln \left(n_{1}+1\right)-\ln \left(n_{2}\right)+n_{2}-\left(n_{1}+1\right) \equiv \bar{\alpha}>\alpha .
$$

Therefore, we have shown that there exists a profitable unilateral deviation from the perfect sorting equilibrium if and only if $\alpha<\bar{\alpha}$ (as defined above).

Now we need to show that the left-hand side of (5) is positive so that $\bar{\alpha}>0$. This can be demonstrated as follows:

$$
\begin{aligned}
\ln \left(n_{1}+1\right)-\ln \left(n_{2}\right)+n_{2}-\left(n_{1}+1\right) & >0 \\
\Longleftrightarrow n_{2}-\left(n_{1}+1\right) & >\ln \left(n_{2}\right)-\ln \left(n_{1}+1\right) .
\end{aligned}
$$

We shall now show that (6) holds. By the mean value theorem, there exists a value $k \in$ $\left(n_{1}+1, n_{2}\right)$ such that:

$$
\ln \left(n_{2}\right)-\ln \left(n_{1}+1\right)=\frac{1}{k}\left[n_{2}-\left(n_{1}+1\right)\right]
$$

As $k \in\left(n_{1}+1, n_{2}\right)$ and $n_{1}+1>1$ by assumption, $1 / k$ is less than one. Thus:

$$
\ln \left(n_{2}\right)-\ln \left(n_{1}+1\right)<n_{2}-\left(n_{1}+1\right)
$$

Hence (6) holds and we have proved the following proposition. 
Proposition 2 There exists a positive number $\bar{\alpha}$ such that a perfect sorting equilibrium exists if and only if $\alpha \geq \bar{\alpha}$.

The intuition behind Proposition 2 is as follows. Recall that $\alpha$ is the strength of own-type bias. For $\alpha>0$ type-2 agents benefit from joining group 2 to be with other type- 2 agents. The cost is that group 1 is smaller and thus faces a less severe free-rider problem in club good provision. If $\alpha$ is large, the benefit exceeds the cost and agents perfectly sort across groups. Otherwise, even when individuals have a positive own-type bias, the free-rider problem may prevent sorting.

\section{$2.2 \quad$ Sacrifice \& Sorting}

One of the central ideas in the economics of religion is that demands for costly sacrifice by religious clubs can inhibit the free-rider problem in collective production. We shall examine here how sacrifice can promote sorting. In particular, we allow clubs to impose a membership cost of $c$. In line with standard interpretations in the literature, this could be interpreted as the cost of time and effort spent on rituals and volunteer work, the psychological cost of accepting new religious beliefs, as well as the stigma imposed by unusual behavioral requirements in terms of diet, dress, sexual behavior, etc.

Type-1 individuals will not want to join group 2 which is larger and thereby faces a more severe free-rider problem. Hence group 2 need not impose a cost to deter mixing. Rather it is the minority group, group 1, which may need to impose a cost to keep the group small and homogeneous. Demanding such a sacrifice can support sorting even when the free-rider problem militates against it. ${ }^{10}$

We can demonstrate this as follows. Working from (5), type-2 agents will not switch if $\bar{\alpha}-c<\alpha$. Therefore, the cost $c$ that makes type-2 agents indifferent is $\bar{c}=\bar{\alpha}-\alpha$ or:

$$
\bar{c}=\ln \left(n_{1}+1\right)-\ln \left(n_{2}\right)+n_{2}-\left(n_{1}+1\right)-\alpha .
$$

All that is left to show is that no type- 1 agent will wish to deviate and join group 2 when joining group 1 costs at least $\bar{c}$. Consider a type- 1 agent $i$. If $i$ plays his part in the

\footnotetext{
${ }^{10} \mathrm{As}$ we have seen, when $\alpha$ is high, sacrifice is not required to produce perfect sorting. Indeed, one can point to examples of a single denomination, whose members face similar membership costs $c$, being sorted into congregations based on ethnicity (e.g. Korean Baptists).
} 
equilibrium and joins 1 , the optimal contribution by all members of 1 to the club good will be $g_{1}^{* *}=y-n_{1}$. Thus, 1 's payoff from joining group 1 , which includes all other type-1 agents only is:

$$
\ln \left(n_{1}\right)+y-n_{1}+\alpha-\bar{c}
$$

If $i$ deviates and joins 2 , then group 2 will consist of $i$ plus all type- 2 members, so the optimal contribution by all members of 2 to the club good will be $g_{2}^{* *}=y-\left(n_{2}+1\right)$. Thus, $i$ 's payoff from joining group 2 is:

$$
\ln \left(n_{2}+1\right)+y-\left(n_{2}+1\right)
$$

This means that $i$ will not deviate if:

$$
\ln \left(n_{1}\right)-\ln \left(n_{2}+1\right)+n_{2}+1-n_{1}+\alpha>\bar{c}
$$

Substituting for $\bar{c}$ :

$$
\ln \left(n_{1}\right)-\ln \left(n_{2}+1\right)+n_{2}+1-n_{1}+\alpha>\ln \left(n_{1}+1\right)-\ln \left(n_{2}\right)+n_{2}-\left(n_{1}+1\right)-\alpha
$$

Rearranging, we have:

$$
\left(n_{1}+1\right)-n_{1}+\left(n_{2}+1\right)-n_{2}+2 \alpha>\ln \left(n_{1}+1\right)-\ln \left(n_{1}\right)+\ln \left(n_{2}+1\right)-\ln \left(n_{2}\right)
$$

By the same reasoning as employed in Proposition 2, using the mean value theorem, we can show that $\left(n_{1}+1\right)-n_{1}>\ln \left(n_{1}+1\right)-\ln \left(n_{1}\right)$ and $\left(n_{2}+1\right)-n_{2}>\ln \left(n_{2}+1\right)-\ln \left(n_{2}\right)$. Therefore, (11) holds for all $\alpha>0$ and no type- 1 agent will deviate.

The result is summarized as follows:

Proposition 3 For $\alpha \in(0, \bar{\alpha})$, there is a choice of membership cost $c>0$ by group 1 such that a perfect sorting equilibrium exists.

Religious groups that demand costlier sacrifices are said to be at high "tension" with society (e.g. Stark \& Bainbridge 1985). By introducing sorting to club models of religion, we can predict that high-tension religious groups are the ones catering to minority types, e.g. those with rare/exotic beliefs. ${ }^{11}$

\footnotetext{
${ }^{11}$ Carvalho $(2015 b)$ makes the same prediction based on a different mechanism related to cultural transmission in groups.
} 
In addition, we can say something about the factors determining the cost required to achieve sorting.

Proposition 4 Suppose $\alpha \in(0, \bar{\alpha})$. The minimum membership cost required for perfect sorting $\bar{c}$ is

(i) strictly decreasing in the size of the minority population $n_{1}$,

(ii) strictly increasing in the size of the majority population $n_{2}$,

(iii) strictly decreasing in the strength of own-type bias $\alpha$.

The minimum cost $\bar{c}$ is given by (9). The results follow from differentiation of (9).

We have established that groups catering to minorities are the ones who demand costly sacrifice. Proposition 4 indicates that the smaller the minority, the costlier the sacrifices demanded by the group. In addition, when individuals are more prejudiced toward their own type, $\alpha$ is high, the minority group can demand less costly sacrifices and still achieve sorting.

\section{Conclusion}

This paper introduces a preference for interacting with one's own type to club models of religion. This is an important feature of social interactions which has thus far been neglected in the literature. In the canonical model (Iannaccone 1992), religious groups demand sacrifices to screen out free riders. This produces an economic benefit by enhancing the efficiency of club good production. We propose an alternative and complementary role for sacrifice in religious clubs. That is, religious groups may provide a sorting mechanism, matching individuals with similar characteristics in social interactions. When individuals exhibit owntype bias, this produces a social benefit for club members. There is an interaction between these economic and social considerations in religious clubs. In particular, we show that the standard free-rider problem in club goods production can inhibit sorting in religious groups. Demands for costly sacrifice can support sorting where it otherwise cannot be achieved. In addition, it is minority groups who attract rare/exotic types that impose such demands. By 
promoting sorting, sacrifice can have an important function in religious clubs, beyond its usual role in limiting free riding.

Future work on this topic could develop a more general model in which groups choose between different types of club goods and an individual's contribution to the club good depends on its fit with his type, along the lines of Alesina \& Spolaore (1997) and Alesina \& La Ferrara (2000). In that case, there may be interesting connections between the screening out of free-riders and type-based sorting. In addition, many religious groups design recruitment activities to increase diversity of their membership. This may reflect preferences at the individual or group level. In terms of our model, some individuals may have an other-type bias, $\alpha<0$, preferring to interact with dissimilar individuals. Alternatively, diversity may provide benefits at the group level, possibly enhancing club goods production by introducing new ideas and contacts (see Page 2007). It would be interesting to explore how a preference for diversity at the individual and/or group level interacts with the free-rider problem to determine sorting in religious clubs.

\section{References}

Aimone, J. A., Iannaccone, L. R., Makowsky, M. D. \& Rubin, J. (2013), 'Endogenous group formation via unproductive costs', Review of Economic Studies 80(4), 1215-1236.

Alesina, A. \& La Ferrara, E. (2000), 'Participation in heterogeneous communities', Quarterly Journal of Economics 115(3), 847-904.

Alesina, A. \& Spolaore, E. (1997), 'Participation in heterogeneous communities', Quarterly Journal of Economics 112(4), 1027-1056.

Berman, E. (2000), 'Sect, subsidy, and sacrifice: an economist's view of ultra-orthodox Jews', Quarterly Journal of Economics 115(3), 905-953.

Berman, E. (2009), Radical, Religious, and Violent: The New Economics of Terrorism, MIT Press, Cambridge, MA.

Bisin, A. \& Verdier, T. (2000), 'Beyond the melting pot: cultural transmission, marriage, and the evolution of ethnic and religious traits', Quarterly Journal of Economics 115(3), 955988.

Boyd, R. \& Richerson, P. J. (1985), Culture and the Evolutionary Process, University of Chicago Press, Chicago, IL. 
Bradshaw, T. (1973), 'Jobseeking methods used by unemployed workers', Monthly Labor Review 96(2), 35-40.

Carvalho, J.-P. (2015a), 'Coordination and culture', working paper, University of California, Irvine.

Carvalho, J.-P. (2015b), 'Identity-based organizations', working paper, University of California, Irvine.

Carvalho, J.-P., Koyama, M. L. \& Sacks, M. (2015), 'Community fragmentation and fragility', working in progress.

Cavalli-Sforza, L. L. \& Feldman, M. W. (1981), Cultural Transmission and Evolution: A Quantitative Approach, Princeton University Press, Princeton, NJ.

Cooper, B. \& Wallace, C. (2004), 'Group selection and the evolution of altruism', Oxford Economic Papers 56, 307-330.

Cornes, R. \& Sandler, T. (1986), The Theory of Externalities, Public Goods and Club Goods, Cambridge University Press, Cambridge, UK.

Currarini, S., Jackson, M. O. \& Pin, P. (2009), 'An economic model of friendship: Homophily, minorities, and segregation', Econometrica 77(4), 1003-1045.

Fiore, A. T. \& Donath, J. S. (2005), 'Homophily in online dating: When do you like someone like yourself?', CHI '05 Extended Abstracts on Human Factors in Computing Systems.

Iannaccone, L. R. (1992), 'Sacrifice and stigma: Reducing free-riding in cults, communes, and other collectives', Journal of Political Economy 100(2), 271-291.

Iannaccone, L. R. (1994), 'Why strict churches are strong', American Journal of Sociology 99(5), 1180-1211.

Iannaccone, L. R. \& Berman, E. (2006), 'Religious extremism: The good, the bad, and the deadly', Public Choice 128, 109-129.

Kalmijn, M. (1998), 'Intermarriage and homogamy: Causes, patterns, trends', Annual Review of Sociology 24, 395-421.

Lazarsfeld, P. \& Merton, R. K. (1954), Friendship as a social process: A substantive and methodological analysis, in M. Berger, ed., 'Freedom and Control in Modern Society', Von Nostrand, New York, NY, pp. 18-66.

Marsden, P. (1987), 'Core discussion networks of Americans', American Sociological Review 52, $122-131$.

McBride, M. (2007), 'Club mormon: Free-riders, monitoring, and exclusion in the lds church', Rationality and Society 19(4), 395-424. 
McBride, M. (2015), 'Why churches need free-riders: religious capital formation and religious group survival', Journal of Behavioral and Experimental Economics 58, 77-87.

McPherson, M., Smith-Lovin, L. \& Cook, J. (2001), 'Birds of a feather: Homophily in social networks', Annual Review of Sociology 27, 415-44.

Olson, M. (1965), The Logic of Collective Action: Public Goods and the Theory of Groups, Harvard University Press, Cambridge, MA.

Page, S. E. (2007), The Difference: How the Power of Diversity Creates Better Groups, Firms, Schools, and Societies, Princeton University Press, Princeton, NJ.

Reskin, B., McBrier, D. \& Kmec, J. (1999), 'The determinants and consequences of workplace sex and race composition', Annual Review of Sociology 25, 302-312.

Schelling, T. (1971), 'Dynamic models of segregation', Journal of Mathematical Sociology 1(1), 143-186.

Schelling, T. C. (1969), 'Models of segregation', American Economic Review Papers and Proceedings 59(2), 488-493.

Shrum, W., Cheek, H. \& Hunter, S. (1988), 'Friendship in school: Gender and racial homophily', Sociology of Education 61, 227-239.

Stark, R. \& Bainbridge, W. S. (1980), 'Networks of faith: Interpersonal bonds and recruitment to cults and sects', American Journal of Sociology 85(6), 1376-1395.

Stark, R. \& Bainbridge, W. S. (1985), The Future of Religion: Secularization, Revival and Religion, University of California Press, Berkeley, CA.

Young, H. P. (1998), Individual Strategy and Social Structure, Princeton University Press, Princeton, NJ. 